\title{
sciendo
}

\section{INTERSPECIFIC HYBRIDS OF ANIMALS IN NATURE, BREEDING AND SCIENCE - A REVIEW}

\author{
Julia Gabryś, Barbara Kij, Joanna Kochan, Monika Bugno-Poniewierska* \\ Department of Animal Reproduction, Anatomy and Genomics, University of Agriculture in Krakow, \\ Mickiewicza 24/28, 30-059 Kraków, Poland \\ •Corresponding author: monika.bugno-poniewierska@urk.edu.pl
}

\begin{abstract}
Interspecific hybrids called hybrids are individuals obtained by crossing two different species. Hybrids are found both in nature among wild animals but also have become attractive in animal husbandry due to the high production features of the F1 generation. Interspecific hybrids are observed in nature most often as a result of crossing closely related species, which is a great danger to the purity of the population of starting species. Interspecies hybrids are also created by man for production purposes. Due to disturbances in gametogenesis processes, they have become a valuable research model. In the article, we describe interspecific hybrids occurring in nature and related problems, interspecific hybrids created for production purposes in animal husbandry, but also research using hybrids as a research model. In the article we also highlight the issues of fertility of individuals obtained from such matings.
\end{abstract}

Key words: interspecific hybrids, hybrids in nature, hybrids in husbandry, hybrids in science

Interspecies hybrids, called also bastards, are synonymous terms describing individuals created as a result of crosses between different species. The first descriptions of this type of organisms were already published in the 8th-7th century BC, for example in Homer's "Iliad". Interspecies crossing became also the subject of research by Charles Darwin (Darwin, 1876). Creation of interspecific hybrids is widely common among plants and animals in order to improve economically important traits for humans (Goodwin, 2007; Bugno-Poniewierska et al., 2015), for they are marked by the effect of heterosis, that is enhancement of quantitative and qualitative characteristics compared to parent species (Proops et al., 2009; Chen and Yu, 2013). Hybrids are not only created by human interference, but are also made in nature (Benirschke, 1967). Furthermore, hybrids are used in scientific research, including in the field of gametogenesis, evolution of karyotypes in the aspect of fertility dysfunction or embryology in the aspect of embryo mortality. 
Interspecies mating is often possible and effective only between several species closely related due to the occurrence of numerous natural barriers. Such barriers are defined as reproductive isolation, protecting the integrity of species and showing different mechanisms of action (McGovern, 1976). Crossbreeding is not possible in many cases because the areas of occurrence of the species concerned do not coincide or border, which is a geographical isolation factor. In turn, the isolating ecological factor means the lack of contact between individuals occurring in one location, which may be caused by these species dwelling different habitats. Reproductive isolation mechanisms also include a direct impact on reproductive efficiency, including differences in the reproductive season, as well as sexual indifference between individuals of different species, which is termed sexual, ethological or psychological isolation (McGovern, 1975). Other important factors are anatomical differences that prevent the act of copulation, such as significant differences in body size or penis mismatch to the vagina, representing a mechanical isolating factor and physiological incompatibility due to biochemical isolation (Kochhar et al., 2002). In the situation where the above-described examples of natural isolation fail and the natural barriers of interspecific crossing are broken, the isolating mechanisms responsible for gamete incompatibility, leading to the inability to fertilize, play an important role. However, if a hybrid zygote develops, isolating post-zygotic factors intervene, causing early deceasing of the embryos, birth defects, and hybrid sterility (McGovern, 1975).

\section{Hybrids in nature}

Hybrid organisms can form without human interference and are common among plants and some animals. In 2007, it was estimated that about $10 \%$ of animal species and $25 \%$ of plants cross with at least one other species (Mallet, 2007). Fish are a relevant example of natural hybridization. In 1955 Hubbs published studies verifying interspecies crossing of Centrarchidae family fish in natural conditions. The species Lepomis euryorus was recognized as a naturally occurring hybrid formed from Lepomis cyanellus (Green Sunfish) $(2 \mathrm{n}=46,2 \mathrm{n}=47$ or $2 \mathrm{n}=48)$ and Lepomis gibbosus (Pumpkinseed) $(2 n=48)$, which was confirmed by tests in breeding conditions. Hybrids showed characteristics that the phenomenon of heterosis arose, reached much larger sizes, were more energetic and dominated in the social hierarchy (Hubbs, 1955).

Hybridization is also a common phenomenon among some species of the Cervidae family. The most well-known examples are hybrids formed between the Scottish red deer (Cervus elaphus scoticus) $(2 \mathrm{n}=68)$ and Rocky Mountain elk (Cervus elaphus nelsoni) $(2 \mathrm{n}=68)$ (Nugent et al., 1987) and between the sika deer (Cervus nippon) $(2 \mathrm{n}=68)$ and red deer (Cervus elaphus) $(2 \mathrm{n}=68)$ (Davidson, 1983). Many hybrids of Scottish red deer and Rocky Mountain elk in the 1970s were caught from wild populations by growers and moved to breeding. The production of interspecific hybrids in breeding has become the subject of deer genetic improvement strategies, and therefore such hybrids have been used extensively (Fennessy et al., 1992). Sika deers were brought to Great Britain over 150 years ago. It was then considered that hybridization between this species and native Scottish red deer was prevented due to significant differences in body size (Powerscourt, 1884). However, in 1987, 
when reviewing the status of sika deer, numerous hybrids were reported in Scotland (Ratcliffe, 1987), which confirmed previous reports and concerns about the threat to the genetic integrity of the native species in England (Lowe and Gardiner, 1975) and Ireland (Harrington, 1982). Robinson et al. (2015) reported a molecular cytogenetic investigation of hybridization between taxonomically distinct species of the Alcelaphini (Alcelaphus buselaphus $2 \mathrm{n}=40 \times$ Damaliscus lunatus $2 \mathrm{n}=36$ ) and the Tragelaphini (Tragelaphus strepsiceros $2 \mathrm{n}=31 / 32 \times$ Tragelaphus angasii $2 \mathrm{n}=55 / 56$ ).

Among wild animals there are also hybrids resulting from the crossing of one wild and one domestic species. For genetically similar species that live in one habitat, crossbreeding was ordinarily prevented by behavioral barriers. However, with the progress of urbanization and the subsequent transformation of the natural environment, many such barriers have been lifted (Wayne and Brown, 2001). This led to unnatural interspecific hybridization, resulting in the weakening of the wild species (Rhymer and Simberloff, 1996). An example of such organisms are wildcats ( $\mathrm{Fe}$ lis silvestris) $(2 \mathrm{n}=38)$ that cross with a domestic cat (Felis catus) $(2 \mathrm{n}=38)$, creating fertile offspring (Ragni, 1993). Such hybrids may be responsible for introgression leading to genetic extinction of the "pure" population of wild cats (Beaumont et al., 2001).

Interspecific hybridization can also occur between many species of the Canidae family, leading to a threat to their population, as exemplified by the crossbreds of the red wolf (Canis rufus) $(2 \mathrm{n}=78)$ and coyote (Canis latrans) $(2 \mathrm{n}=78)$ (Roy et al., $1996)$ and the gray wolf (Canis lupus) $(2 \mathrm{n}=78)$ and domestic dog (Canis familiaris) $(2 \mathrm{n}=78)$ (Randi et al., 2000; Vilà et al., 2003). Wolf populations are gradually decreasing, leading to significant impoverishment of this species (Wayne et al., 1992). In most areas of Europe, wolf populations living in the immediate vicinity of humans often intercross with domestic dogs. Reproductive isolation between these species is not fully developed due to their close phylogenetic relationship and sharing of natural habitats (Vilà et al., 1997; Randi et al., 2000). For this reason, in 1994 it was hypothesized that many rebuilt wolf populations consist mainly of hybrids resulting from interspecific hybridization (Butler, 1994).

In the context of hybridization of closely related hybrids, studies on the occurrence of hybrid zones are conducted (Dureje et al., 2012).

\section{Interspecific hybrids in animal production and utility}

The literature review reports the creation of this type of crossbreds in order to improve the features of interest from the point of view of breeding such as: weight gain, better resistance to diseases, increase in productivity, efficiency and also stamina and strength (Travis, 1990; Short, 1997). The representative marked by these features is a mule $(2 \mathrm{n}=63)$. It is a crossbred formed by crossing a domestic horse (Equus caballus $)(2 \mathrm{n}=64)$ and a male donkey (Equus asinus) $(2 \mathrm{n}=62)$, characterized by greater strength and stamina than horses. Moreover, it has a calmer disposition than horses and greater resistance to hard working conditions. These animals reach larger body sizes and exhibit greater tractive force relative to the horse (Travis, 1990). For these reasons, mules have been used as draft and pack animals for many years and generate a lot of interest for many researchers. 
Hybrids are also used in the fur industry. Individuals resulting from the crossing of the silver fox (Vulpes vulpes fulvus) $(2 \mathrm{n}=34+\mathrm{B} ; \mathrm{B}=0-10)$ and the polar fox (Vulpes lagopus $)(2 \mathrm{n}=48,2 \mathrm{n}=49$ or $2 \mathrm{n}=50)$ are rare in nature, and such crosses are obtained by insemination (Cole and Shackelford, 1947; Gustavsson et al., 1988). The popularity of hybrids $(2 \mathrm{n}=40,2 \mathrm{n}=41,2 \mathrm{n}=42)$ (Makinen and Gustavsson, 1982; BugnoPoniewierska et al., 2015) increased along with the recipients' interest in their fur, and thus, along with the growing profits brought by hybrid breeding. When a female polar fox is crossed with a male red fox, a larger number of offspring is obtained compared to purebred litters; in addition, hybrids reach larger body sizes (Gustavsson et al., 1988). Hybrids are also marked by an exceptional density and quality of the coat, whose structure is assessed as silky and fluffy. Depending on the varieties of foxes used for hybridization, animals may show different coloration (Jakubczak et al., 2011).

Wild animals have also been used in the production of interspecies hybrids. $\mathrm{Hu}-$ man-controlled hybridization of domestic animals with their wild ancestors has been conducted on a large scale for many years to hone or improve the value of animal products and to produce new breeds of companion animals (De Lavigne, 2015).

One of the longest-documented bastards is the wild boar $(2 n=36)$ and a domestic pig $(2 n=38)$ hybrid $(2 n=37)$ (Benirschke et al., 1967). Those organisms have been used economically as meat with flavor similar to wild game. Due to the large consumer interest in wild boar meat, the possibility of supplying the adequate amount of this raw material to the market was sought, which resulted in the creation of hybrids kept on farms to this day (Kozdrowski and Dubiel, 2004).

Another example of an interspecific hybrid where the effect of heterosis was used is a hybrid of American bison (Bison bison) $(2 \mathrm{n}=60)$ with domestic cattle (Bos taurus $)(2 \mathrm{n}=60)$. The production of this hybrid was aimed at combining the features of these two species: body size and resistance of buffalo with carcass quality and growth rate of cattle. Hybrids named "cattalo" $(2 n=60)$ were defined as hybrids of less than half bison parentage (Mason, 1975), and "beefalo" $(2 \mathrm{n}=60)$ was defined as 3/8 bison and 5/8 domestic cattle (Makobo et al., 1981). In Europe in the 1980s, a hybrid of the European bison (Bison bonasus) $(2 \mathrm{n}=60)$ and domestic cattle (Bos taurus) $(2 \mathrm{n}=60)$ was created, known as the żubron $(2 \mathrm{n}=60)$, and is still produced to this day. These animals are marked by good assimilation of feed, fast pace of weight gain, as well as high resistance to adverse environmental conditions. Meat of such hybrids can be considered as an attractive alternative to beef, so that it may emerge to be a promising solution for breeders interested in innovative directions of animal production (Sumiński, 1987; Łozicki et al., 2017).

A different instance of a hybrid produced to improve production characteristics such as meatiness and coat was a hybrid of goat (Capra hircus) $(2 \mathrm{n}=60)$ and sheep (Ovis aries) $(2 \mathrm{n}=54)$, informally called "geep" or "shoat" $(2 \mathrm{n}=57)$. These two species are taxonomically and genetically distant and do not cross easily, however, there have been reports of such individuals in nature (Mine et al., 2000). They have been described as extremely muscular animals about the size of a large ram. They have a black, silver and gray coat, and a goat-like coat. Unfortunately, confirmed reports of live hybrids of goats and sheep were extremely rare, which made the crossbred not 
used in industry (Stewart-Scott et al., 1990). Interest in creating interspecies hybrids with wild species also applies to equidae. One of the first successful attempts to cross Burchell's zebra (Equus quagga burchellii) $(2 \mathrm{n}=44$ or $2 \mathrm{n}=45)$ with a horse (Equus caballus $)(2 \mathrm{n}=64)$ took place in 1902, and in 1913, thanks to the Bureau of Animal Industry, Philippines, the Grévy's zebra was successfully crossed (Equus grevyi) (2n =46) with a donkey (Equus asinus) $(2 \mathrm{n}=62)$. In order to improve the method of obtaining such hybrids, a few years later similar tests were carried out, obtaining eight hybrid individuals using a zebra stallion and a horse mare. A Grévy's zebra was used in the study due to its larger size and apparently longer coat than other zebra species. This is how zebroids were born $(2 n=55)$. Dr. W.E. Hasting, who conducted the experiment, recognized hybrids as intelligent, gentle and durable animals (Roberts, 1929). However, due to the greater difficulty in obtaining zebroids, mules enjoy greater popularity in use to this day.

Interspecies hybrids produced to create new companion breeds are also known. One of the most popular cat breeds in the world, the Bengal cat, is the result of a cross between a domestic cat (Felis catus) $(2 \mathrm{n}=38)$ and a leopard cat (Prionailurus bengalensis) $(2 \mathrm{n}=38)$ (Johnson, 1991). Domestic cats are also crossed with servals (Leptailurus serval) $(2 \mathrm{n}=38)$ to produce the largest breed of companion cats named Savannah (Wheeler, 2011). Female domestic cat and male wild feline species are usually used to create cat breeds in captivity, and fertilization occurs due to natural mating or, less often, insemination (Davis et al., 2015).

Interspecific hybridization has also given rise to many breeds of dogs, such as Czechoslovakian wolfdog, Saarloos wolfdog, Lupo Italiano or Kunming dog, which also tried to improve or introduce new functional features (De Lavigne, 2015). Czechoslovakian wolfdog $(2 n=78)$ was created as a result of hybridization between wild Carpathian grey wolves $(2 n=78)$ and German Shepherds $(2 n=78)$ as a military experiment, in order to create hard working dogs with increased endurance and improved sensory abilities (like better night vision). The task of these hybrids was primarily to protect the borders of Czechoslovakia during the Cold War. Currently, this breed is consolidated and entered into the Fédération Cynologique Internationale (FCI). Dogs of this breed are bred commercially around the world as companion and defensive animals (Smetanová et al., 2015).

\section{Production of hybrids of wild animals in captivity}

The phylogenetic, anatomical and physiological similarity of some species does not create barriers to their crossbreeding. However, in the natural environment, such cross-species crossbreeding is not possible due to geographical and behavioral restrictions. Such examples are species of lion and tiger $(2 n=38)$, living in a significant geographical distance and having relevant different behavior. The crosses of these species, such as ligers, that are hybrids of male lion (Panthera leo) $(2 n=38)$ and female tiger (Panthera tigris) $(2 \mathrm{n}=38)$ or tigons (male tiger $\times$ female lion), are created in captivity in zoos or as a result of targeted activities of breeders. However, the formation of hybrids of lions and tigers is considered unethical, due to the susceptibility of these animals to obesity and the occurrence of birth defects resulting in death. Ligers and tigons also show disturbed social adaptation with representatives 
of parent species, caused by behavioral features not belonging to any of the mother organisms (Rafferty, 2019).

\section{Interspecific hybrids as a research model}

Interspecific hybrids have become the subject of many scientific studies. The unique features of hybrids, such as intra-individual and inter-individual variability in the number of chromosomes or gametogenesis disorders, which consequently lead to infertility, have made these animals a valuable research model.

Understanding the cause of hybrid sterility is one area that engages many scientists. The findings to date confirm Haldane's observation from 1922 that it is male sex among F1 offspring derived from crossbreeding between two animal species that usually shows sterility (Haldane, 1922). An important discovery in this field was the failure of meiotic chromosome pairing in hybrids of moth from the genus Pygaera (Federley, 1911). In the 1930s, research on Epilobium hybrids (Michaelis, 1933) and some Drosophila pseudoobscura crosses (Dobzhansky, 1934) were published, which showed the sterility of hybrids, despite proper pairing during synapsis, proving that different mechanisms are responsible for chromosomal homology and there is not always a causal connection between the sterility of hybrids and dysfunctional meiotic divisions. Therefore, a hypothesis was suggested according to which hybrid sterility may occur at two levels - chromosomal and gene. The chromosomal type of infertility is caused by a numerical and/or morphological difference between the karyotypes of parental organisms, therefore, it is impossible to properly pair chromosomes during meiosis, which leads to impaired gametogenesis. On the other hand, the genetic type is a consequence of the interaction between genomes inherited from both parental organisms (Dobzhansky, 1934).

In 1969 (Iványi et al., 1969) a study was published showing the complete sterility of male hybrids obtained as a result of crossing wild mice with C67BL/10 females. Males were marked by reduced testicles and arresting of spermatogenesis at the stage of primary spermatocyte or spermatogonium. However, when the same wild males were crossed with females of the $\mathrm{C} 3 \mathrm{H}$ inbred, fertile offspring were obtained. Further research has determined that the main cause of hybrid sterility may be a factor associated with the histocompatibility-2 (H-2) complex, located on chromosome 17, and the interaction of the gene/genes located on the chromosome no. 9 resulted in impaired spermatogenesis (Iványi et al., 1969; Iványi and Mickova, 1971).

However, gene products that can affect the sterility of hybrids or event sequences leading to their sterility are difficult to identify. In order to attempt to determine the cause of infertility in mammals, an experiment was conducted during which the laboratory mouse (Mus musculus) $(2 \mathrm{n}=40)$ was crossed with the tobacco mouse (Mus poschiavinus) $(2 \mathrm{n}=40)$ and only partial fertility of the hybrid was found. After backcrossing hybrids with a laboratory mouse, a reduction of litters by more than half relative to the size of the parent species litters was observed. Reduced fertility has been associated with the occurrence of nondisjunction during meiosis and the subsequent production of genetically unstable gametes. It has also been suggested that the nondisjunction observed in hybrids may be a result from genetic or structural heterozygosity, which leads to the formation of chromosome trivalents, arising 
in the formation of two aneuploid daughter cells (Tettenborn and Gropp, 1970). It has also been shown that many pre-implantation embryos had a high percentage of chromosomal abnormalities, which may suggest the ability of sperm to fertilize despite chromosomal imbalance, hence small litters during backcrossing represented only by individuals arising from genetically balanced gametes (Gropp et al., 1970). However, following further studies on mouse hybrids, results suggested that, despite the occurrence of 14 Robertsonian translocations in Mus poschiavinus, leading to a drastic change in its karyotype, the nondisjunction in the gametes of hybrids does not have to be their consequence, but may result from other chromosomal or genic differences (Cattanach and Moseley, 1973).

Some relationships were found between the infertility of Muridae hybrids and Drosophilidae hybrids. It has been shown that in both these interspecies hybrids, sterility was associated with the changed testicular size and dysfunctional spermatogenesis. Both organisms are also characterized by abnormal meiotic division, during which different numbers of univalents arise, and arrested spermatogenesis usually before the formation of primary spermatocytes (Forejt and Iványi, 1974). Dobzhansky, after conducting numerous studies on hybrids of Drosophila pseudoobscura $(2 n=8)$ and Drosophila persimilis $(2 n=8)$, propounded a statement that the degree of impairment of spermatogenesis is controlled by at least eight genes that are scattered throughout the genome. The author also states that the development of testicles is related with its genetic structure which was confirmed by tests with mutual testicular transplantation (Dobzhansky, 1951), as well as the lack of hormonal abnormalities in sterile mouse hybrids (Forejt and Iványi, 1974).

Equine hybrids are an excellent example of the sterility of hybrids resulting from chromosomal disorders. In mules, based on histological studies, it was shown that their infertility was associated with disorders of cell division during spermatogenesis (Benirschke et al., 1964). In addition, it has been shown that, despite the welldeveloped interstitial tissue of the nucleus, the mule seminal tubules are lined with only one or two layers of cells, have an irregular intersection and a significantly smaller diameter than the horse seminal tubules (McGovern, 1976). It has also been proved that the mitotic activity of spermatogonia is normal, however, synapsis, occurring in the phase of the first meiotic division, is abnormal and irregular. Disability in the pairing of homologous chromosomes renders that primary spermatocytes degenerate even before the metaphase stage, therefore it is impossible to identify spermatids or spermatozoa (Makino, 1955). Many authors associate incorrect synapsis occurrence with morphological and structural differences between paternal (donkey) and maternal (horse) chromosomes that prevent the formation of homologous pairs (Benirschke et al., 1962; Trujillo et al., 1962). Analogous studies were executed on zebroids (donkey $\times$ Grant's zebra and horse $\times$ Grévy's zebra), and the results proved the importance of the lack of homology between the chromosomes of parental organisms (King et al., 1965). It has become natural to suppose that it is the pairing failure during meiosis that can cause hybrid sterility.

Another example is research on fox hybrids confirming the effect of the lack of chromosome homology of parent species on the sterility of their offspring (Graphodatsky and Radzhabli, 1981; Makinen and Gustavsson, 1982; Bugno-Poniewierska et 
al., 2015). The Arctic fox karyotype (Vulpes lagopus) is marked by the occurrence of three variants of chromosome sets $(2 n=48,2 n=49$ or $2 n=50)$, which is caused by polymorphic variability of Robertsonian translocation (Gustavsson and Sundt, 1965). The karyotype of the red fox (Vulpes vulpes) varies in the number of B chromosomes that can range from 0 to 8 . The basic set of chromosomes (A) is 34 (Belyajev et al., 1974; Świtoński, 1988; Graphodatsky et al., 2000). Bugno-Poniewierska et al. (2015) showed, in the interspecies hybrids of these fox species, the number of set A chromosomes ranged from 35 to 44 and $\mathrm{B}$ chromosomes from 0 to 4 . Only six individuals showed a fixed number of set A chromosomes and five hybrids did not inherit B chromosomes at all. Authors observed not only inter-individual but also intra-individual differences in the number of chromosomes.

During the meiosis, hybrid genomes resulting from parental karyotypes produce unbalanced daughter cells - univalents, multivalents or not fully paired bivalents (Bugno-Poniewierska, unpublished data). Hybrid sterility is caused by arresting cell division at the stage of first meiosis prophase. Histological studies have determined that the zygotene stage proceeds correctly, analogously to fertile animals, while the pachytene stage exhibits degeneration, leading to the arrest of a further subdivision process, directly affecting the formation of spermatids (Świtoński, 1981; Gustavsson et al., 1988).

The use of fluorescence in situ hybridization in research, allowing reliable identification of chromosomes, enabled localization of homologous blocks in chromosomes of various species, as well as their visualization in gametes (Raudsepp and Chowdhary, 1999). This technique has been used in an in-depth analysis of chromosome behavior during meiotic divisions in cells derived from the tissue of the hybrid fox testicle (Bugno-Poniewierska et al., 2014). Test results confirmed earlier observations (Wipf and Shackelford, 1949; Nyberg, 1980; Gustavsson et al., 1988), associating hybrid sterility with disruption of the first meiotic division at the stage of prophase, more specifically pachytene. In addition, the FISH technique was used to conduct $\mathrm{X}$ and $\mathrm{Y}$ chromosome pairing analysis, which showed the variable behavior of these bivalent structures at each stage of prophase I. The results suggest that the meiosis disorder results from early dissociation of the bivalent, lack of pair formation or loss of one of the heterosomes, which as a consequence may lead to arresting cell division and sterility of hybrids (Bugno-Poniewierska et al., 2014).

Meiotic preparations obtained from the same individuals became a research object in which, using the immunofluorescence technique with SP1 and SP3 proteins, bivalent structures and their deviations (multivalents, univalents and not fully paired bivalents) were analyzed. Frequent foci of phosphorylated histones H2AH $\gamma$ (Ser 139) have been localized to the meiotic block in late pachytene, which indicates a disruption of the meiotic division in male fox hybrids, resulting in a high percentage of apoptotic cells in the gonads of these animals and their infertility (BugnoPoniewierska et al., unpublished data).

\section{Interspecific hybrids as a model for infertility testing}

The technique of combining gametes from two different species is also used, among others, to assess the sperm's fertilization capacity and broadly understood 
sperm-egg interaction in various animals. Already in 1976, Yanagimachi and colleagues conducted a study involving the fertilization in laboratory conditions of Syrian hamster (Mesocricetus auratus) eggs lacking a zona pellucida by human sperm. The results confirmed the possibility of using hamster egg cells to pre-assess the fertilizing capacity of human sperm. This method has since found application in scientific research and was called the oocyte penetration test (Yanagimachi et al., 1976). This method was also used in livestock production, using hamster eggs to assess the potential for fertilization of cattle and horses semen. Studies have shown that spermatozoa that failed to penetrate the hamster oolemma are not capacitive and are not able to carry out an acrosome reaction, which indicates their reduced potential for fertilization in vivo (Brackett et al., 1982). In addition, studies using the oocyte penetration test showed that morphologically abnormal sperm have a much lower ability to penetrate the oolemma (Marsh et al., 1987).

The assessment of the potential for fertilization of spermatozoa is also used in research in the context of the protection of endangered Felidae species (Wildt et al., 1983; 1988). In 1990, research was undertaken to assess the ability of leopard cat spermatozoa to penetrate the zona pellucida of domestic cat oocytes, as well as hamster oocytes without zona pellucida. It has been shown that sperm have reproductive potential for a closely related domestic cat to the same extent as for a hamster, suggesting that the formation of hybrids between species so far taxonomically distant is possible. Conducting this type of tests is especially valuable for understanding the functioning of gametes in endangered species, where classical research is limited due to difficult access to animals, and also offer the opportunity to develop new and improve existing methods of assisted animal reproduction (Howard and Wildt, 1990).

As indicated above, interspecific hybrids are found in nature, but are also made by humans for utility purposes and for basic research. However, those found in nature have a close taxonomic relationship, which in consequence does not lead to infertility, but is a huge threat to the purity of the species.

Man-made hybrids are characterized by exuberance of features valuable in terms of usability, but most are infertile. However, this does not translate into productive efficiency due to the fact that heterosis is only visible in the F1 generation. From the point of view of breeding economics, F1 generations are not cost-effective for further crossing due to the disappearance of heterosis. Interspecific hybrids are also a valuable model for basic research on understanding the mechanisms of fertility disorders, embryology, as well as any research on endangered species.

\section{Acknowledgments}

The work was carried out as part of the activity of the Cytogenetics Scientific Club, University of Agriculture in Krakow.

\section{References}

B eaumont M., B arratt E.M., Gottelli D., Kitchener A.C., Daniels M.J., Pritc hard J.K., B r u ford M.W. (2001). Genetic diversity and introgression in the Scottish wildcat. Mol. Ecol., 10: 319-336. 
B e ly aj ev D.K., Volobujev V.T., R a d zhabli S.J., Trut L.N. (1974). Polymorphism and mosaicism for additional chromosomes in silver foxes. Genetika, 10: 58-67.

B e n i s c h ke K. (1967). Sterility and fertility of interspecific mammalian hybrids. In: Comparative Aspects of Reproductive Failure, Benirschke K. (ed.). Springer, Berlin, Heidelberg, pp. 218-234.

B e n i s c h ke K., B row nhill L.E., B e a th M.M. (1962). Somatic chromosomes of the horse, the donkey and their hybrids, the mule and the hinny. J. Reprod. Fertil., 4: 319-326.

Benirschke K., Low R.J., Brownhill L.E., Caday L.B., de Venecia-Fernandez J. (1964). Chromosome studies of a donkey-grevy zebra hybrid. Chromosoma, 15: 1-13.

B rackett B.G., C of on e M.A., B o i c e M.L., B ous quet D. (1982). Use of zona-free hamster ova to assess sperm fertilizing ability of bull and stallion. Gamete Res., 5: 217-227.

Bugno-Poniewierska M., Paw lina K., Jakubczak A., Jeżewska-Witkowska G. (2014). Analysis of genomic instability in primary spermatocytes of interspecific hybrids of the red fox (Vulpes vulpes) and the Arctic fox (Alopex lagopus). Folia Biol., 62: 307-312.

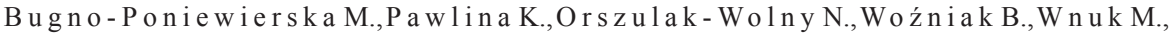
Jakubczak A., Jeżewska-Witkowska G. (2015). Cytogenetic characterization of the genome of interspecies hybrids (Alopex-Vulpes). Ann. Anim. Sci., 15: 81-91.

Bugno-Poniewierska M., Witarski W., Kuchta-Gładysz M., Jakubczak A., Jeżewska-Witkowska G. Severe asynapsis in spermatocytes of interspecific hybrids of the silver fox (Vulpes vulpes) and the blue fox (Alopex lagopus) leads to pachytene I arrest as a result of sustained $\mathrm{H} 2 \mathrm{AX} \gamma$ phosphorylation. Unpublished data.

B u t l e r D. (1994). Bid to protect wolves from genetic pollution. Nature, 370: 497.

C a t t a n a c h B.M., M o s e le y H. (1973). Nondisjunction and reduced fertility caused by the tobacco mouse metacentric chromosomes. Cytogenet. Cell Genet., 12: 264-287.

$\mathrm{C}$ hen Z.J., Yu H.H. (2013). Genetic and epigenetic mechanisms for polyploidy and hybridity. In: Polyploid and Hybrid Genomics, Chen Z.J., Birchler J.A. (eds). Wiley, Oxford, pp. 335-354.

Cole L.J., Shackelford R.M. (1947). Fox hybrids. Transactions of the Wisconsin Academy of Science, Arts and Letters, 38: 315-322.

D a rw in C.R. (1876). The effects of cross and self fertilisation in the vegetable kingdom. London: John Murray.

D a vi d s o n M.N. (1983). Sika deer. In: The Handbook of New Zealand Mammals, King C. (ed.). Auckland: Oxford University Press, pp. 468-477.

D a vi is B.W., S e a bury C.M., B r a sh e ar W.A., Li G., Ro e 1 ke - Parker M., Murphy W.J. (2015). Mechanisms underlying mammalian hybrid sterility in two feline interspecies models. Mol. Biol. Evol., 32: 2534-2546.

De Lavigne G. (2015). Free Ranging Dogs - Stray, Feral or Wild? Raleigh, North Carolina, $447 \mathrm{pp}$.

Dobzhansky T.H. (1934). Studies on hybrid sterility. I. Spermatogenesis in pure and hybrid Drosophila pseudoobscura. Z. Zellf. Mikr. Anat., 21: 169-223.

D o b zh a n sky T.H. (1951). Experiments on sexual isolation in Drosophila. X. Reproductive isolation between Drosophila pseudoobscura and Drosophila persimilis under natural and under laboratory conditions. Proc. Natl. Acad. Sci., 37: 792-796.

Dureje L., Macholan M., Baird S.J., Pialek J. (2012). The mouse hybrid zone in Central Europe: from morphology to molecules. Folia Zool. 61 (3-4): 308-318.

Fe derley H. (1911). Vererbungsstudien an der Lepidopterengattung Pygaeru. Archiv Rassen- und Gesellschafts. Biol. Bd., 8: 281-338.

Fenness y P.F., Tate M.L., Johnstone P.D. (1992). Hybridisation between red deer and other species. Proc. Austral. Assoc. Anim. Breed Genet., 9: 469-472.

F o r e j t J., I v á n y i P. (1974). Genetic studies on male sterility of hybrids between laboratory and wild mice (Mus musculus L.). Genet. Res., 24: 189.

G o o dw in D. (2007). Equine learning behaviour: what we know, what we don't and future research priorities. Behav. Proc., 76: 17-19.

Graphodatsky A.S., Radzhabli S.I. (1981). Comparative cytogenetics of three Canid species (Carnivora, Canidae): I. Structural rearrangements of chromosomes in the evolution of the karyotype. Genetika, 17: 985-989.

Graphodatsky A.S., Yang F., O'Brien P.C.M., Serdukova N., Milene B.S., Tri- 
fon ov V. (2000). A comparative chromosome map of Arctic fox, red fox and dog defined by chromosome painting and high resolution G-banding. Chromosome Res., 8: 253-263.

Gropp A., Tettenborn U., von Lehmann E. (1970). Chromosome variations on the Robertson type in the tobacco mouse, M. Poschiavinus, and its hybrids with the laboratory mouse. Cytogenetics, 9: 9-23.

Gust a v s s o n I., S und t C.O. (1965). Chromosome complex in the family Canidae. Hereditas, 54: $248-254$.

Gu st a v s s o n I., Ś w i t oń s k i M., L a r s s o n K., P lö e n L. (1988). Synaptonemal complex analysis of spermatocytes in hybrids of silver fox and blue fox. J. Hered., 79: 338-343.

H a ld a n e B.S. (1922). Sex ratio and unisexual sterility in animal hybrids. J. Genet., 12: 101.

Harrington R. (1982). The hybridization of red deer (Cervus elaphus L. 1758) and Japanese sika deer (Cervus nippon nippon Temminck 1838). Transactions of the International Congress of Game Biology, 14: 559-571.

H o w a rd J., W il d t D.E. (1990). Ejaculate-hormonal traits in the leopard cat (Felis bengalensis) and sperm function as measured by in vitro penetration of zona-free hamster ova and zona-intact domestic cat oocytes. Mol. Reprod. Dev., 26: 163-174.

H u b b s C. (1955). Hybridization between fish species in nature. Syst. Zool., 4: 1-20.

I vá n y i P., M i c k o vá M. (1971). Further studies on genetic factors in the ninth linkage group influencing reproductive performance in male mice. In: Immunogenetics of the H-2 System, Lengerova A., Vojtiskova M. (eds). Symposium, Liblice near Prague, September 1970: Proceedings. Basel, Karger, 1971, pp. 104-119.

I vá n y i P., D e ma n t P., Voj t i s k ova M., I ván y i D. (1969). Histocompatibility antigens in wild mice (Mus musculus). Transplant Proc., 1: 365-367.

J a kubczak A., Bugno-Poni ew i erska M., J eżew ska-Witkowska G., Horecka B., $\mathrm{B}$ u ś - K i c m a n M. (2011). Genetic differentiation of intergeneric hybrids of Blue Frost foxes and their original forms based on microsatellite polymorphism. Ann. Anim. Sci., 11: 219-227.

J o hn s o n G. (1991). The Bengal cat. Greenwell Springs (LA): Gogees Cattery.

K ing J.M., Short R.V., Mutto D.E., Hamerto n J.L. (1965). The reproductive physiology of male zebra-horse and zebra-donkey hybrids. J. Reprod. Fertil., 9: 391.

Ko chhar H.P.S., Appa Rao K.B.C., Luciano A.M., Totey S.M., Gandolfi F., Bas r u r P.K., K ing W.A. (2002). In vitro production of cattle-water buffalo (Bos taurus - Bubalus bubalis) hybrid embryos. Zygote, 10: 155-162.

K o z d row s ki R., D u bi e l A. (2004). The effect of season on the properties of wild boar (Sus scrofa L.) semen. Anim. Reprod. Sci., 80: 281-289.

L o w e V.P.W., Gardin e r A.S. (1975). Hybridization between red deer (Cervus elaphus) and sika deer (Cervus nippon) with particular reference to stocks in N.W. England. J. Zool. London., 177: 553-566.

Łozicki A., Olech W., Dymnicka M., Florowski T., Adamczak L., Arkuszewska E., Ni e mie c T. (2017). Nutritive value and meat quality of domestic cattle (Bos taurus), zubron (Bos taurus $\times$ Bison bonasus) and European bison (Bison bonasus) meat. Agr. Food. Sci., 26: 118-128.

Mak in en A., Gu s t a v s s o n I. (1982). A comparative chromosome-banding study in the silver fox, the blue fox, and their hybrids. Hereditas, 97: 289-297.

Makin o S. (1955). Notes on the cytological feature of male sterility in the mule. Experientia, 11: 224.

Mak ob o A.D., B u c k N.G., Li ght D.E., L e th o la L.L. (1981). A note on the growth of Beefalo crossbred calves in Botswana. Anim. Sci., 33: 215-217.

Ma 11 e t J. (2007). Hybrid speciation. Nature, 446: 279-283.

Mars h S.K., B olt o n V.N., B r a u d e P.R. (1987). The effect of morphology on the ability of human spermatozoa to penetrate zona-free hamster oocytes. Hum. Reprod., 2: 499-503.

Ma s on I.L. (1975). Hybridization between bison and cattle. Food and Agriculture Organization, Rome.

M c G overn P.T. (1975). The barriers to interspecific hybridization in domestic and laboratory mammals. I. Gametic isolation and hybrid inviability. Br. Vet. J., 131: 691-706.

M c G overn P.T. (1976). The barriers to interspecific hybridization in domestic and laboratory mammals. II. Hybrid sterility. Br. Vet. J., 132: 68-75. 
Michae lis P. (1933). Entwicklungsgeschichtlich-genetische Untersuchungen an Epilobium. II. Die Bedeutung des Plasmas fur die Pollenfertilitat des Epilobium luteum-hirsutum Bastardes. Zschr. Ind. Abst. Vererb., 65: 1-71.

M in e O.M., K e dikilwe K., N d e b e le R.T., N s o s o S.J. (2000). Sheep-goat hybrid born under natural conditions. Small Rumin. Res., 37: 141-145.

Nug e n t G., P a rkes J.P., Tu s t in K.G. (1987). Changes in the density and distribution of red deer and wapiti in northern Fiordland. New Zeal. J. Ecol., 10: 11-21.

Nyberg K. (1980). Forseke med artkrysning mellom blarev (Alopex lagopus) og rodrev (Vulpes vulpes) ved hjelp av kunsu'g saedeoverfering (Crossing blue fox to red fox using artificial insemination). Nord. Vet. Med., 32: 132.

P ow er s c ourt V. (1884). On the Acclimatization of the Japanese Deer at Powerscourt. Proceedings of the Zoological Society of London, 52: 207-209.

Proops L., Burden F., Osthaus B. (2009). Mule cognition: a case of hybrid vigour? Anim. Cogn., 12: 75-84.

R a ffe r t y J.P. (2019). Liger (Internet). Encyclopædia Britannica, https://www.britannica.com/animal/ liger (access: 10.02.2020).

R a g n i B. (1993). The crucial problem of in vivo identification of wildcat and recognition of hybrids with domestic cats. Institute of Zoology, Peruglia University, Italy.

Randi E., Lucchini V., Christensen M. F., Mucci N., Funk S.M., Dolf G., Loes c h c k e V. (2000). Mitochondrial DNA variability in Italian and East European wolves: detecting the consequences of small population size and hybridization. Cons. Biol., 14: 464-473.

R a t c liffe P.R. (1987). Distribution and current status of Sika deer (Cervus nippon) in Great Britain. Mammal Rev., 17: 39-58.

R a u d s e p p T., Chow dhary B.P. (1999). Construction of chromosome-specific paints for metaand submetacentric autosomes and the sex chromosomes in the horse and their use to detect homologous chromosomal segments in the donkey. Chromosome Res., 7: 103-114.

R h y m e r J.M., S i m b e r l o ff D. (1996). Extinction by hybridization and introgression. Annu. Rev. Ecol. Syst., 27: 83-109.

R obert s E. (1929). A zebra-horse cross. J. Hered., 20: 545-548.

Robinson T.J., Cernohorska H., S chulze E., Duran-Puig A. (2015). Molecular cytogenetics of tragelaphine and alcelaphine interspecies hybrids: hybridization, introgression and speciation in some African antelope. Biol. Lett., 11: 20150707.

R oy M.S., Geffen E., S mith D., Wayne R.K. (1996). Molecular genetics of pre-1940 red wolves. Conserv. Biol., 10: 1413-1424.

S h o r t R.V. (1997). An introduction to mammalian interspecific hybrids. J. Hered., 88: 355-357.

Smetanová M., Černá Bolfíková B., Randi E., Caniglia R., Fabbri E., Galavern i M., Kutal M., Hulva P. (2015). From wolves to dogs, and back: genetic composition of the Czechoslovakian Wolfdog. PLoS ONE, 10: e0143807.

Stewart-S cott I.A., P e arce P.D., Dewes H.F., Thompson J.W.L. (1990). A case of a sheep-goat hybrid in New Zealand, N Z Vet. J., 38: 7-9.

S u mińs k i E. (1987). Żubronie (in Polish). Prz. Hod., 5: 18-21.

Ś w i toń s k i M. (1981). Robertsonian translocation in the blue fox (Alopex lagopus) and its effect on the fertility. Genet. Polonica, 22: 463-474.

Św i toń s k i M. (1988). B chromosomes in the fox (Vulpes vulpes), their nature, distribution, inheritance and effects. Ann. Agr. Univ. Pozn., p. 174.

Tet te n b or n U., Grop p A. (1970). Meiotic nondisjunction in mice and mouse hybrids. Cytogenet. Genome Res., 9: 272-283.

Travis L. (1990). The mule. J. A. Allen \& Co, London, 150 pp.

Trujillo J.M., S tenius C., Christian L.C., Ohno S. (1962). Chromosomes of the horse, the donkey, and the mule. Chromosoma, 13: 243-248.

Vilà C., S avola in en P., Maldona do J.E., A mori m I.R., R i c e J.E., Hone y c ut t R.L., Cranda 11 K.A., Lundeberg J., Wayne R.K. (1997). Multiple and ancient origins of the domestic dog. Science, 276: 1687-1689.

Vilà C., Walker C., Sundqvist A., Flagstad Ø., Andersone Z., Casulli A., Kojola I., Valdmann H., Halverson J., Ellegren H. (2003). Combined use of maternal, 
paternal and bi-parental genetic markers for the identification of wolf-dog hybrids. Heredity, 90: 17-24.

Wayne R.K., B rown D.M. (2001). Hybridization and conservation of carnivores. In: Carnivore Conservation, Gittleman J.L., Funk S.M., Macdonald D., Wayne R.K. (eds). Cambridge University Press: Cambridge, UK., pp. 145-162.

Wa yn e R.K., L ehman N., A 11 ard N.W., Hon e y cutt R.L. (1992). Mitochondrial DNA variability of the gray wolf: genetic consequences of population decline and habitat fragmentation. Conserv. Biol., 6: 559-569.

W h e e le r J.C. (2011). Savannah cats. Edina (MN): ABDO Publishing Company, pp. 8-18.

Wildt D.E., Bush M., Howard J.G., O'Brien S.J., Meltzer D., van Dyk A., Ebed e s H., B r a n d D.J. (1983). Unique seminal quality in the South African cheetah and a comparative evaluation in the domestic cat. Biol. Reprod., 29: 1019-1025.

W il d t D.E.,P hi 11 i p s L.G., S i m m o n s L.G., C h a k r a b o r t y P.K., B row n J.L., H o w a r d J.G., Te a r e A., B u s h M. (1988). A comparative analysis of ejaculate and hormonal characteristics of the captive male cheetah, tiger, leopard and puma. Biol. Reprod., 38: 245-255.

Wi p f L., S ha c kel for d R.M. (1949). Chromosomes of a fox hybrid (Alopex-Vulpes). Proc. Natl. Acad. Sci. USA., 35: 468-472.

Yan a i m a ch i R., Yan a g i m a ch i H., R o ger s B.J. (1976). The use of zona-free animal ova as a test-system for the assessment of the fertilizing capacity of human spermatozoa. Biol. Reprod., 15: $471-476$.

Received: 7 V 2020

Accepted: 23 VII 2020 